\title{
DELUSIONAL DRUG DEPENDENCE- AN ENTITY
}

\author{
Amil H. Khan ${ }^{1}$, Amrit Pattojoshi2 ${ }^{2}$ Aleem Siddiqui' ${ }^{3}$ Sagar Lavania ${ }^{4}$, Lagnajit Dash ${ }^{5}$ \\ ${ }^{1}$ Associate Professor, Department of Psychiatry, BRD Medical College, Gorakhpur. \\ ${ }^{2}$ Associate Professor, Department of Psychiatry, Hi-Tech Medical College, Bhubaneshwar. \\ ${ }^{3}$ Associate Professor, Department of Psychiatry, ERA Medical College, Lucknow. \\ ${ }^{4}$ Associate Professor, Department of Psychiatry, SN Medical College, Agra. \\ 5Junior Resident, IMS and SUM Hospital. Bhubaneshwar.
}

\section{ABSTRACT}

\section{BACKGROUND}

Patients with substance dependence exhibit various kinds of beliefs about their substance taking behaviour. Despite having clear problems, they deny them and believe that they can control themselves. No one has examined the delusional intensity of these beliefs. In this study, we tried to measure the delusional intensity of the beliefs by using Brown assessment of belief scale (BABS).

\section{MATERIALS AND METHODS}

Two core beliefs, first "I don't have any problem with my substance intake" and second "I can quit substance whenever I want" were selected and then measured on BABS scale for delusional intensity. Total 64 patients were assessed.

\section{RESULTS}

42 patients reported having first belief and 22 patients had second belief; 31 with first belief and 17 with second belief had fixity of their belief in delusional intensity.

\section{CONCLUSION}

Delusional fixity of beliefs is common in patients of substance dependence, which should be assessed while planning any treatment and rehabilitation strategy for these patients.

\section{KEYWORDS}

Delusion, BABS, Dependence.

HOW TO CITE THIS ARTICLE: Khan AH, Pattojoshi A, Siddiqui A, et al. Delusional drug dependence- an entity. J. Evolution Med. Dent. Sci. 2017;6(72):5172-5176, DOI: 10.14260/jemds/2017/1123 \section{BACKGROUND \\ Caregivers of substance dependent patients always wonder} what is going on in the patient's mind. Why even loss of job, divorce, loss of children, homelessness, illness, etc. do not deter the addict from substance taking behaviour. To a nonaddict, the behaviour of an addict seems irrational and illogical. But addict seems very comfortable with it. Addict believes that life would be unliveable without drug. So they continue drugs at any cost. Patients develop many cognitive distortions in order to maintain their drug seeking behaviour. Cognitive distortions are ways of perceiving reality that can distort the truth of a situation. Everyone uses cognitive distortion. Addicts and other psychiatric patients use them more frequently. Their life is so wretched that they cannot function without these distortions. Many patients deny that they have any problems with substance at all. Many would believe that they can control themselves at any time despite repeated failures. Denial, personalisation, labelling, magnification, minimisation, distorted mental filters and irrational emotional reasoning are main cognitive distortions in patients of drug dependence.

Financial or Other, Competing Interest: None.

Submission 24-06-2016, Peer Review 06-08-2016,

Acceptance 13-08-2016, Published 07-09-2017.

Corresponding Author:

Dr. Amrit Pattojoshi,

Associate Professor,

Department of Psychiatry,

Hi-Tech Medical College, Bhubaneshwar.

E-mail:dramritp@yahoo.com

DOI: $10.14260 /$ jemds $/ 2017 / 1123$
Personality variables are psychological factors that attempt to explain why certain people are drawn to substance use and abuse. ${ }^{1}$ Oluwatelure (1995) found a positive correlation between extroversion and substance abuse. ${ }^{2,3}$ Some studies found a strong relationship between neuroticism and substance abuse. ${ }^{4}$ Few studies have found a positive relationship between psychoticism and substance abuse.5,2,3 High scorers on psychoticism exhibit some personality and behavioural traits such as impulsivity, aggressiveness, egocentrism and antisocial tendencies ${ }^{6}$ and these traits have been shown to correlate with substance abuse. ${ }^{7}$

Researchers have studied high levels of negative affect and an enduring desire for arousal and increased positive affect. In one study, ${ }^{8}$ Drug use in general has been found to correlate with anti-social personality disorder. Rebelliousness and high levels of aggression have been found to be related to substance abuse.7,8 Lavelle et al (1991) showed that drug users were shrewd, tough-minded, anxious, streetwise and experience-seeking. ${ }^{9}$ Further, Ekstrand (1985) reported that drug users seemed to be immature, compulsive and possess low self-esteem and are incapable of managing failure. ${ }^{10}$ Also Shedler and Block (1990) indicate that frequent drug users were maladjusted, socially alienated and deficient in impulse control and manifestly distressed. ${ }^{11}$

Generally, all the psychological factors that induce individuals to abuse substances invariably lead to psychiatric disorders. For example, it has been reported earlier how amphetamine and other psycho-stimulants can induce amphetamine psychosis that resembles paranoid schizophrenia in patients that abuse these substances. 
Furthermore, abuse of hallucinogens, e.g. lysergic acid diethylamide (LSD) can lead to conceptual distortion of time and distance, impair rational judgement and loss of ability to separate fantasy and fact, a flashback of frightening experiences and to death from suicide among other physical harmful effects. ${ }^{12}$

The Brown Assessment of Belief Scale (BABS) has been developed to rate the degree of conviction and insight of patient's beliefs. ${ }^{13}$ These beliefs include delusions as well as the beliefs that may underlie obsessional thinking and phobias. Obsessions and delusions have traditionally been viewed as dichotomous phenomena with obsessions being defined as intrusive ego-dystonic thoughts about which the patient maintains insight. On the other hand, delusions have been defined as false beliefs held firmly by the patient without insight into the irrationality of the content of the belief. However, obsessions and delusions might be better conceptualised as existing on a continuum of insight that ranges from good insight to poor insight (Overvalued ideation) to no insight (Delusional thinking). Such a continuum of insight may be present in a variety of psychiatric disorders such as obsessive-compulsive disorder, body dysmorphic disorder, anorexia nervosa and hypochondriasis as well as in disorders traditionally considered psychotic such as schizophrenia and delusional disorder..$^{13}$ No one has assessed beliefs or insight of patients with substance dependence using BABS.

It is based on the premise that insight itself consists of a number of dimensions. Thus, the BABS rate a number of dimensions that underlie delusional and nondelusional beliefs. These dimensions are conviction, perception of others' views of beliefs, explanation of differing views, fixity of ideas, attempt to disprove beliefs, insight and ideas/ delusions of reference. ${ }^{13}$
Aim

To examine delusional intensity of two beliefs, first "I don't have any problems with my substance intake" and second "I can quit it whenever I want" by Brown Assessment of Belief Scale (BABS).

\section{MATERIALS AND METHODS}

After obtaining approval of the Local Ethics Committee, data were collected from March to July 2011 on outpatients from the De-Addiction Clinic, Department of Psychiatry at the Nehru Hospital, BRD Medical College, Gorakhpur, UP.

\section{Patients who fit the following Criteria were included in} the Study
a. Male.
b. More than 18 years of age.
c. Diagnosed as substance dependent according to DSM-IV TR (any substance except nicotine).
d. Minimum 5 years' duration of dependence.

All participants were informed and written consents were taken. Two beliefs were selected. First "I don't have any problems with my substance intake" and second "I can quit it whenever I want." These beliefs were assessed on BABS scale to find out their degree of fixity. Total 64 participants were assessed, 42 patients had first belief "I don't have any problem with my substance intake" and 22 had second belief "I can quit it whenever I want." Then the data was analysed with appropriate statistical methods using SPSS version 15.

\section{RESULTS}

Table 1(a) and 1(b) shows the distribution of sociodemographic variables of two groups. Both groups were homogeneous regarding age, years of education, income, occupation and marital status.

\begin{tabular}{|c|c|c|c|c|}
\hline Variables & $\begin{array}{c}\text { Group A } \\
(\text { Mean } \pm \text { SD) }\end{array}$ & $\begin{array}{c}\text { Group B } \\
(\text { Mean } \pm \text { SD) }\end{array}$ & $\begin{array}{c}F \\
(\mathrm{df}=1,64)\end{array}$ & $\mathbf{p}$ \\
\hline Age & $\begin{array}{c}29.60 \pm 8.16 \\
(21.44-37.76)\end{array}$ & $\begin{array}{c}29.00 \pm 5.98 \\
(34.98-23.02)\end{array}$ & 0.363 & 0.697 \\
\hline Years of Education & $\begin{array}{c}9.86 \pm 4.86 \\
(14.72-5.0)\end{array}$ & $\begin{array}{c}12.00 \pm 3.72 \\
(15.72-8.28)\end{array}$ & 0.968 & 0.388 \\
\hline
\end{tabular}

\begin{tabular}{|c|c|c|c|c|c|c|}
\hline \multicolumn{2}{|c|}{ Variables } & $\begin{array}{c}\text { Group A } \\
\text { N } 42(\%)\end{array}$ & $\begin{array}{c}\text { Group B } \\
\text { N } 22(\%)\end{array}$ & $\chi^{2}$ & df & $\mathbf{P}$ \\
\hline \multirow{3}{*}{ Income } & $<5000$ & $10(23.8)$ & $2(9.09)$ & \multirow{3}{*}{ - } & \multirow{3}{*}{-} & \multirow{3}{*}{$\begin{array}{c}0.329 \\
\text { (Fisher's) }\end{array}$} \\
\hline & $5000-10000$ & $22(52.3)$ & $13(59.0)$ & & & \\
\hline & $>10000$ & $10(23.8)$ & $7(31.8)$ & & & \\
\hline \multirow{3}{*}{ Occupation } & Student & $12(28.5)$ & $6(27.2)$ & \multirow{3}{*}{-} & \multirow{3}{*}{-} & \multirow{3}{*}{$\begin{array}{c}0.370 \\
\text { (Fisher's) }\end{array}$} \\
\hline & Employed & $14(33.3)$ & $8(36.3)$ & & & \\
\hline & Unemployed & $16(38.0)$ & $8(36.3)$ & & & \\
\hline \multirow{2}{*}{ Marital Status } & Single & $18(42.8)$ & $9(40.9)$ & \multirow{2}{*}{0.536} & \multirow{2}{*}{1} & \multirow{2}{*}{0.428} \\
\hline & Married & $24(57.1)$ & $13(59.1)$ & & & \\
\hline
\end{tabular}




\begin{tabular}{|c|c|c|c|}
\hline & $\begin{array}{c}\text { Belief 1 (I don't have any Problem } \\
\text { with my Substance Intake) }\end{array}$ & $\begin{array}{c}\text { Belief 2 (I can quit it } \\
\text { whenever I want) }\end{array}$ & Total \\
\hline Total no. of patients (N= 64) & $42(65.6 \%)$ & $22(34.4 \%)$ & 64 \\
\hline Mean duration of dependence (yrs.) & 7.2 & 6.4 & 6.8 \\
\hline Type of substance (no. \%) & & & \\
Alcohol & & $9(14.1 \%)$ & $32(50.0 \%)$ \\
Opioid & $23(35.9 \%)$ & $4(06.2 \%)$ & $11(17.1 \%)$ \\
Multiple & $7(10.9 \%)$ & $8(12.4 \%)$ & $18(28.1 \%)$ \\
& $10(15.6 \%)$ & $1(01.6 \%)$ & $03(04.8 \%)$ \\
\hline Mean BABS score & $2(03.2 \%)$ & 22.8 & 22.6 \\
\hline No. of patients with delusional intensity & 22.4 & $17(26.5 \%)$ & $48(74.8 \%)$ \\
\hline No. of patients with delusional intensity & $31(48.3 \%)$ & & $7(10.9 \%)$ \\
(type of drug) & & $3(04.6 \%)$ & $26(40.5 \%)$ \\
Alcohol & $6(10.9 \%)$ \\
Cannabis & $19(29.6 \%)$ & $1(0.4 \%)$ & $14(21.8 \%)$ \\
Opioid & $(06.2 \%)$ & $1(01.6 \%)$ \\
\hline Multiple & $0(0.0 \%)$ & & \\
\hline \multicolumn{2}{|c|}{ Table 2. BABS Score and Dependence distribution of Beliefs } \\
\hline
\end{tabular}

Mean duration of dependence was 6.8 years [Table 2]; 32 (50\%) patients were of alcohol, 11 (17.1\%) had cannabis dependence, 18 (28.1\%) had opioid dependence and 3 $(4.6 \%)$ had multiple substance dependence. Mean BABS score was 22.6; 48 (74.8\%) patients have shown delusional intensity for their belief. In these patients $26(40.5 \%)$ were alcohol dependent, 7 (10.8\%) were cannabis dependent, 14 $(21.6 \%)$ were opioid dependent and 1 was dependent on multiple substances.

Data was analysed separately for each belief. For first belief [Table 2], 42 (65.6\%) patients recognised themselves with this thought. Mean age was $29.60 \pm 8.16$ years. Mean duration of dependence was 7.2 years. Mean total BABS score was $22.4 ; 31(48.3 \%)$ patients scored 24 out of 24 and lacked insight and were completely delusional about their belief. In these 31 patients 19 (29.6\%) were alcohol dependent, 4 (6.2\%) were cannabis dependent and 8 (12.4\%) were opioid dependent.

22 patients had belief 2 - Their mean age was $29.00 \pm 5.98$ years. Mean duration of dependence was 6.4 years. Mean total BABS score was 22.8; 17 (26.5\%) patients scored 24 out of 24 and lacked insight and were completely delusional about their belief. In these 17 patients 7 (10.9\%) were alcohol dependent, 3 (4.6\%) were cannabis dependent, 6 (9.4\%) were opioid dependent and $1(1.6 \%)$ were multiple substance dependence.

\section{DISCUSSION}

This is the first study which has explored the delusional intensity of the beliefs of patients with substance use disorders. A significant proportion of patients have beliefs, which reach at delusional intensity of conviction. These are the patients who had frequent relapses and are treatment resistant. How do we explain these psychotic phenomena in these patients? Is there any similarity between delusion and drug dependence? Delusion is false, firm, fixed belief which is out of keeping with individual's social, educational and cultural background. Out of all these properties, fixity is the main characteristic. It is the conviction and fixity, which determines delusional intensity and makes it difficult to change. If it is shakable, then it is not delusion but an idea. An idea is simply a product of stream of thought. Belief is an idea, which is thought to be true. We believe in something, because we believe it is true. We have belief in God, because we believe it as truth. So, something which is true will be held with more conviction and fixity. In delusion, belief is false but it is false for others and not for person who harbours it. For the person, this belief is as true as any other true belief.

For delusion belief should be out of keeping with person's social, educational and cultural background. This is an arbitrary assumption, which has no biological meaning or basis. For an atheist belief in God is delusion and for any religious person non-belief in God is delusion. Presence of personal distress associated with the belief is more relevant than this social and cultural assumption.

So, basically any belief which is fixed, unshakable and persisting contrary to evidence and producing personal distress then it is delusion.

Similarly, fixity of substance taking behaviour or act leads to dependence. While dealing with patients of substance dependence (SD), many patients denied any problem with substance despite giving evidences against it. They blame others or minimise their problems. They would claim that they can quit without any effort and have strong belief with strong conviction that it is in their control as we found in our study. When evidences provided against their belief then they would blame on other factors. There is proportion of patient in which all rehabilitation and preventive measures have failed and still patient remain in denial stage. Some patients would accept, but did not have any control over their substance taking behaviour. This fixity of behaviour is mainly delusional dependence.

The extent to which a person believes a drug is harmful and the perceived prevalence of use by others are two 
psychological variables correlating with substance abuse have been explored in some studies. A study by Kozel and Adams (1986) reported that marijuana use peaked in 1978, when almost $11 \%$ of high school seniors reported daily use. ${ }^{14}$ At that time only $12 \%$ of seniors believed there was risk associated with occasional use and $35 \%$ believed there was risk with regular use, whereas in $19855 \%$ of seniors reported daily use, $25 \%$ of high school seniors believed marijuana was harmful if used occasionally and $70 \%$ believed it was harmful if used regularly. ${ }^{14}$ These findings indicate that as beliefs change, so does behaviour. The dramatic increase in marijuana use in the 1990s was mainly among those adolescents who believed the drug was harmless ${ }^{15}$ (USDHHSS, 1994).

Many patients start taking substance for an experiment. ${ }^{16}$ They report that they want to feel these substances and claimed that they can control themselves. This belief that they can control themselves persisted even when they developed full blown dependence. They do not want any treatment and do not see this behaviour as problematic. They insist that it is something which they can overcome easily and right now they do not want. This is a belief which they believe as truth despite it is false and persisting contrary to evidences presented to them. This is surely a delusion, delusional dependence.

Studies have repeatedly shown a positive relationship between psychoticism and substance abuse. ${ }^{5,9}$ High scorers on the psychoticism scale exhibit some personality and behavioural traits, e.g. aggressiveness, impulsivity, egocentrism and impersonal feelings and anti-social tendencies. ${ }^{6}$ These are linked with the initiation and maintenance of drug use. ${ }^{7}$

There is biological link between delusion and dependence. Pleasure seeking behaviour is guided by reward center, i.e. nucleus accumbens (NAc) in brain. Almost all the drugs and substances used for pleasure release dopamine (DA) in this center and activations of this center are perceived as pleasure. ${ }^{17}$ Even sexual act activate this center. So, any activity is pleasurable because it activates this reward center. Gradually, a person wants more activation, more pleasure and then become dependent. It may be concluded that seeking hyperdopaminergic state in NAc is the dependent state. Whatever is providing highest dopamine state in NAc, person is dependent on that. Delusion is hyperdopaminergic state and with DA antagonist it can be reduced. So both delusion and dependence are associated with hyperdopaminergic state in NAc.

Delusional belief is associated with comfort and is ego syntonic. This belief explains individual's feeling and experiences. During delusional memory when the patient is aware that something is happening around him and which is distressing and painful then he searches for an explanation. By whatever method, he develops an idea which explains his feeling or experiences and then he thinks it true so it becomes a belief. Now this belief reduces his distress and gives him comfort, so it is held with more conviction, reaching at delusion level.

- Idea + truth= belief.

- Belief + conviction = fixed belief.

- Fixed belief + morbid origin + comfort $=$ delusion .
Patients with substance dependence (SD) frequently relapse due to their delusional belief that they can control themselves at any point of time. During craving they think that taking substance once or twice will not do any harm and they search for explanations for taking substance and when they got one (this is last; not more than once; only to relieve anxiety; no one understand me, etc.), then they again start the same behaviour.

\section{Limitations}

Small sample is surely a limitation in this study, needing further assessment with large sample and it should be compared with normative data. Effects of antipsychotics have been not explored in this study, which warranted further investigation.

\section{CONCLUSION}

Delusional fixity of beliefs related with substance use is common in patients of substance dependence. It should be assessed while planning any treatment and rehabilitation strategy for these patients.

\section{REFERENCES}

[1] Davison GC, Neale JM, Kring AM. Abnormal psychology. $9^{\text {th }}$ edn. New York: John Wiley and Sons 2004.

[2] Oluwatelure FA. The personality of alcohol and nonalcohol users. In: Obot IS. edr. Epidemiology and control of substance abuse in Nigeria. Jos: CRISA 1983.

[3] Oluwatelure FA. Drug beliefs and personality of undergraduate alcohol users and abstainers. Nigerian Journal of Basic and Applied Psychology 1995;4(2\&7):50-6.

[4] Killen JD, Robinson TN, Haydel KF, et al. Prospective study of risk factors for the initiation of cigarette smoking. Journal of Consulting and Clinical Psychology 1997;65(6):1011-6.

[5] Ifeagwazi MC. Personality characteristics of a group of arrested drug users and non-users. Nigerian Journal of Psychological Research 2005;4:9-15.

[6] Carey G, Dilalla DL. Personality and psychopathology: genetic perspectives. Journal of Abnormal Psychology 1994;103(1):32-43.

[7] Anderson T, Magnusson D, Wennberg P. Early aggressiveness and hyperactivity as indicators of adult alcohol problems and criminality: a prospective longitudinal study of male subjects. Studies on Crime and Crime Prevention 1997;6(1):7-20.

[8] Davison GC, Neale JM. Abnormal Psychology. $8^{\text {th }}$ edn. New York: John Wiley and Sons 2001.

[9] Lavelle T, Hammersley R, Forsyth A. Personality as an explanation of drug use. Journal of Drug Issues 1991;21(3):593-604.

[10] Ekstrand BR. Psychology: its principles and meanings. New York: CBS College Publishing Company 1985.

[11] Shedler J, Block J. Adolescents drug use and psychological health. A longitudinal inquiry. American Psychologists 1990;45(5):612-30.

[12] Egbuchulam CJ. Commonly abused drugs and Nigerian youths. Owerri, Nigeria: Skillmark Media Ltd., 2000. 
[13] Eisen JL, Phillips KA, Baer L, et al. The brown assessment of beliefs scale: reliability and validity. American Journal of Psychiatry 1998;155(1):102-8.

[14] Kozel NJ, Adams EH, Centers for Disease control. National surveillance of cocaine use and related health consequences. Morbidity and Mortality Weekly Report 1982;31(20):265-8, 273.

[15] United States Department of Health and Human Services. National Survey results on drug use from monitoring the future study (1975-1993). Rockville, Maryland: National Institute on Drug Abuse 1994.
[16] Ball SA, Carroll KM, Rounsaville BJ. Sensation-seeking, substance abuse and psychopathlology in treatmentseeking and community cocaine abusers. Journal of Consulting and Clinical Psychology 1994;62(5):10537.

[17] Goldstein RZ, Volkow ND. Drug addiction and its underlying neurobiological basis: neuroimaging evidence for the involvement of the frontal cortex. American Journal of Psychiatry 2002;159(10):164252. 